\title{
Efeito das vitaminas D e E no teste de tolerância à glicose em ovelhas gestantes
}

Priscilla Marques do Nascimento", Marcela Romanini Faria, Débora Dias de Carvalho, Carolinne Bróglio Deusdado, Aline Alberti

Morgado, André Storti Martins, Clara Satsuki Mori, Maria Claudia Araripe Sucupira

Universidade de São Paulo (USP), São Paulo, Brasil

*Autor correspondente

e-mail: pmnascimento@usp.br

\section{Resumo}

Durante o periparto, ovelhas estão mais predispostas a transtornos nutricionais e metabólicos. Dentre as enfermidades metabólicas nos pequenos ruminantes domésticos, a toxemia da prenhez (TP) é a doença que ainda necessita de estudos em relação à patogenia e à terapia. Estudos têm apontado a resistência à insulina como um dos importantes fatores envolvidos na gênese da TP, principalmente nas ovelhas escore de condição corporal superior a 3,5 e que não conseguem compensar a resistência insulínica periférica, fisiológica no pré-parto. Têm-se relacionado baixo status sérico das vitaminas D e E à resistência insulínica em animais e no homem. Assim, para avaliar o impacto do uso parenteral, pela via intramuscular profunda, dessas vitaminas. Vinte e quatro ovelhas previamente submetidas a protocolo de sincronização concluído com monta assistida, no $100^{\circ}$ dia de gestação, foram distribuídas em três grupos de oito ovelhas cada, respeitando o delineamento de blocos casualizados, de acordo com o número de fetos e escore de condição corporal. As ovelhas do grupo controle (GC) receberam veículo oleoso; as ovelhas do grupo tratado com vitamina D (GD), receberam essa vitamina na dose de $70.000 \mathrm{UI} / \mathrm{kg}$ de P.V. (produto manipulado a 3.000 .000 $\mathrm{UI} / \mathrm{mL}$ de vitamina D3); e as ovelhas do grupo tratado com vitamina E (GE) receberam a vitamina na dose 60UI/kg de P.V. (produto manipulado contendo 450 UI/mL $\alpha$-tocoferol). Entre 120 e 125 dias de gestação, as ovelhas foram submetidas ao teste de tolerância à glicose (TTG) para avaliar a sensibilidade insulínica. Foi administrado 0,18g de glicose por kg de P.V., e o sangue foi coletado aos $-15,0,2,5,10,15,20,30,45$, 60, 90, 120 minutos da infusão. Para calcular a biodisponibilidade da administração da glicose em relação à produção de insulina, utilizou-se a medida estatística que apresenta de forma resumida um conjunto de dados de um indivíduo sobre o tempo após uma única aplicação, denominada área sobre a curva (AUC). Não foram observadas diferenças entre os valores de AUC para as ovelhas GC, GD e GE de glicose $(P=0,995)$ e de insulina ( $\mathrm{P}=0$,659). Portanto, nas condições do estudo acima, não se observou efeito do uso parenteral (IM) 
de elevadas doses das vitaminas D e E na sensibilidade insulínica de ovelhas gestantes. Auxílio Pesquisa FAPESP, processo ํㅡㄹ 2014/17297-9. 